\title{
Competências para a sustentabilidade organizacional: uma revisão sistemática
}

\author{
EDSON LUIS KUZMA \\ UNIVERSIDADE ESTADUAL DO CENTRO OESTE, IRATI - PR, BRASIL \\ SÉRGIO LUIS DIAS DOLIVEIRA \\ Universidade ESTADUAL do CENTRO OESTE (UNICENTRO), IRATI - PR, BRASIL \\ ADRIANA QUEIROZ SILVA \\ UnIVERSIDADE ESTADUAL do CENTRO OESTE (UNICENTRO), IRATI - PR, BRASIL
}

\begin{abstract}
Resumo
A relação estabelecida entre as competências organizacionais e a sustentabilidade organizacional deve ser objeto de reflexão e constante aprimoramento, visando à convergência dos objetivos individuais e da organização para a sustentabilidade dos negócios e o atingimento das estratégias empreendidas. Portanto, considerando-se a relevância das discussões que envolvem as competências societais e a sustentabilidade organizacional, a presente pesquisa buscou analisar e explorar a relação existente entre as competências organizacionais e a sustentabilidade aplicada ao contexto empresarial. Para tanto, optou-se pelo desenvolvimento de uma revisão sistêmica das publicações de cunho quantitativo e qualitativo a partir de buscas por meio do Portal de Periódicos da Coordenação de Aperfeiçoamento de Pessoal de Nível Superior (Capes) e da base de dados da Associação Nacional de Pós-graduação e Pesquisa em Administração (Anpad) nos últimos seis anos, considerando o período de 2010 a 2015. As pesquisas abordam, em unanimidade, o tratamento da relação entre as competências organizacionais e a sustentabilidade aplicada às organizações. Os resultados apontam para distintas linhas de compreensão e de produção, que agregam conhecimento à discussão que envolve a temática. Os estudos tratam de competências organizacionais que são desenvolvidas em empresas pela articulação de ações com foco nas dimensões econômica, social e ambiental na composição do ser sustentável, conforme é apresentado no artigo.
\end{abstract}

Palavras-chave: Competência organizacional. Sustentabilidade organizacional. Revisão sistêmica.

\section{Skills for organizational sustainability: a systematic review}

\section{Abstract}

The relationship established between organizational skills and organizational sustainability should be reflected and constantly improved to align the goals of the individual and the organization, in order to achieve business sustainability and success of the strategies adopted. Against this backdrop and considering the relevance of discussions involving societal competencies and organizational sustainability, this research seeks to analyze and explore the relationship between organizational competencies and sustainability, applied to a business context. To this end a systemic review of quantitative and qualitative publications was conducted, using CAPES Portal of Scientific Journals (Periódicos CAPES) and ANPAD- National Association of Graduate Studies and Research in Administration database. The research focused on studies published from 2010 to 2015, and all publications approach the relationship between organizational competencies and sustainability, applied to organizations. The results show distinct lines of understanding and production adding value to the debate on the issue. The publications focus on organizational competencies that are developed in companies by articulated activities focusing on economic, social and environmental dimensions of sustainability.

Keywords: Organizational Competencies. Organizational Sustainability. Systemic Review.

\section{Competencias para la sostenibilidad organizacional: una revisión sistemática}

\section{Resumen}

La relación establecida entre las competencias organizacionales y la sostenibilidad organizacional debe ser objeto de reflexión y constante perfeccionamiento, buscando la convergencia de los objetivos individuales y de la organización para la sostenibilidad de los negocios y el logro de las estrategias emprendidas. Por lo tanto, considerando la relevancia de las discusiones que involucran las competencias societarias y la sostenibilidad organizacional, la presente investigación buscó analizar y explorar la relación existente entre las competencias organizacionales y la sostenibilidad aplicada al contexto empresarial. Para ello, se optó por el desarrollo de una revisión sistémica de las publicaciones de carácter cuantitativo y cualitativo a partir de búsquedas a través del Portal de Periódicos de la Coordinación de Perfeccionamiento de Personal de Nivel Superior (Capes) y de la base de datos de la Asociación Nacional de Posgrado e Investigación en Administración (Anpad) en los últimos seis años, considerando el período de 2010 a 2015. Las investigaciones abordan unánimemente el tratamiento de la relación entre las competencias organizacionales y la sostenibilidad aplicada a las organizaciones. Los resultados apuntan hacia distintas líneas de comprensión y de producción, que agregan conocimiento a la discusión en torno a la temática. Los estudios tratan de competencias organizacionales que se desarrollan en empresas por la articulación de acciones con foco en las dimensiones económica, social y ambiental en la composición del ser sostenible, como se presenta en el artículo.

Palabras clave: Competencia organizacional. Sostenibilidad organizacional. Revisión sistémica. 


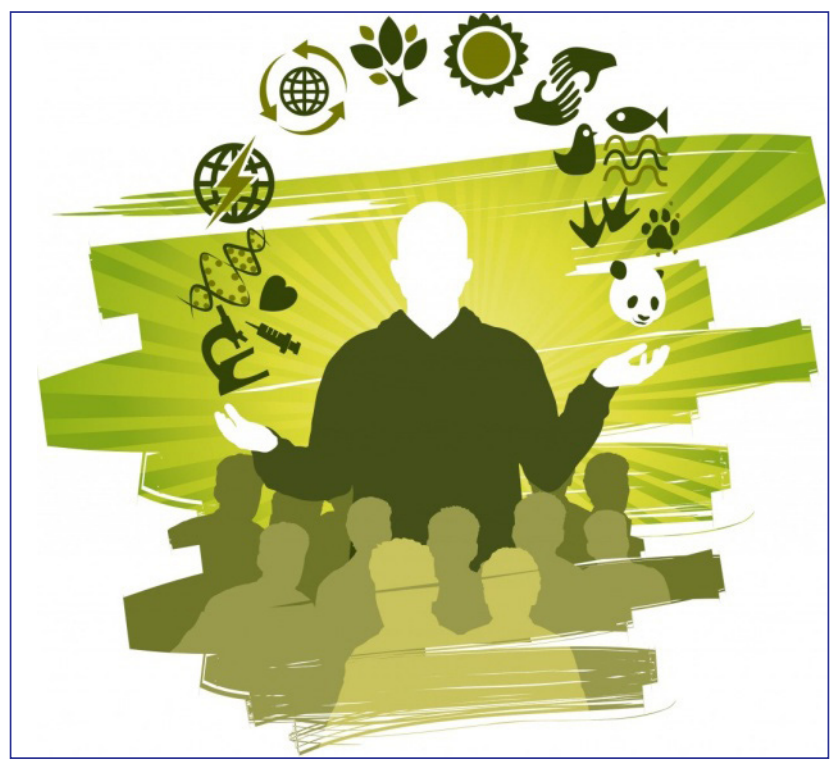

\section{INTRODUÇÃO}

A articulação da temática das competências organizacionais com os desafios da sustentabilidade constitui um campo rico de possibilidades de pesquisa ainda a ser explorado. A concepção do conceito de competência societal partindo da temática da sustentabilidade é estabelecida como a capacidade de lidar com os impactos sociais e ambientais, evidenciando a necessidade de obtenção de lucros e geração de riquezas, desenvolvendo a gestão das organizações em múltiplas faces de interesse (SCHALTEGGER, HANSEN e LUDEKE-FREUND, 2016). É estabelecido um diálogo entre as empresas e a sociedade em direção à construção de uma forma diferenciada de gestão e de produção de bens e serviços.

As habilidades e qualificações dos colaboradores são empregadas, de forma que sejam utilizadas a serviço da organização. Por meio da gestão dessas competências, amplificam-se as potencialidades dos indivíduos, buscando convergir seus objetivos aos da organização. Nesse sentido, a assimilação de questões socioeconômico-ambientais pelas organizações e a consequente necessidade de desenvolvimento de gestores para atender a essa agenda político-social fazem-se presentes. A orientação do direcionamento da empresa com vistas ao atendimento de metas e à melhoria dos processos e procedimentos deve passar pelo emprego das capacidades individuais e conjuntas de colaboradores e gestores.

O estudo das competências e dos respectivos modelos que permitem sua operacionalização nas organizações surge como resposta a um anseio por incrementar as habilidades individuais e colocá-las a serviço do direcionamento assumido pela organização. A gestão por competências exige a retomada da valorização da relação entre organização e indivíduo, pois ressalta a importância do ser humano competente na efetividade dos inúmeros processos inseridos em uma rotina empresarial (MUNCK, SOUZA e SAGUI, 2011). Nesse ambiente de reconhecimento do indivíduo como sendo valoroso à empresa, levantam-se fatores que influenciam a realidade socialmente construída, na qual organização, pessoas e meio ambiente compartilham recursos, espaço, território, anseios, confluindo em ações que fomentem o estabelecimento de uma forma de desenvolvimento sustentada.

A sustentabilidade aplicada ao contexto das organizações envolve relações múltiplas de troca entre o aspecto social, econômico e ambiental, almejando a seguridade e o bem-estar das gerações presentes e futuras a partir do uso racional e consciente dos recursos disponíveis (BRUNSTEIN, SCARTEZINI e RODRIGUES, 2012). Nesse cenário, as empresas desempenham um 
papel de fundamental importância, sobretudo pelo comprometimento da gestão voltada aos valores sustentáveis e às práticas de desenvolvimento produtivo, de competição e de tecnologias aplicadas na minimização da ação empresarial no meio.

A articulação entre práticas de gestão sustentáveis e os modelos de competências adotados pelas organizações tendem a resultar em procedimentos benéficos para a sociedade, a economia e o meio ambiente. $\mathrm{O}$ conhecimento suficientemente claro a respeito das estratégias empresariais, anseios pessoais e interesses da sociedade permite maior participação dos diversos stakeholders em situações envoltas por condicionantes sustentáveis.

Portanto, tendo em vista tais considerações, o objetivo da presente pesquisa é explorar a relação existente entre as competências organizacionais e a sustentabilidade aplicada ao contexto empresarial. A temática foi abordada por meio de uma revisão sistêmica, identificando, de acordo com critérios específicos de inclusão e exclusão, os estudos mais pertinentes à discussão do tema de pesquisa. $O$ desenvolvimento do estudo é apresentado a seguir.

\section{FUNDAMENTAÇÃO TEÓRICA}

\section{Competências organizacionais}

A gestão das competências, compreendida dentro de um sistema maior de gestão organizacional, é um processo contínuo que tem por ponto inicial a estratégia da organização e suas metas, que direcionam as ações para a captação e o desenvolvimento das competências necessárias ao cumprimento de seus objetivos. De acordo com Fleury e Fleury (2008), quando relacionado com o ambiente de trabalho, o conceito de competência assume facetas tanto individuais quanto coletivas, e até mesmo organizacionais. Quando analisadas pela ótica individual, dizem respeito à formação e ao desenvolvimento das pessoas, e quando estudadas pelo âmbito organizacional, referem-se aos aspectos conceituais da organização: estratégia, negócio e competitividade. Para os autores, a competência individual é tida como um saber agir responsável e reconhecido, que implica mobilizar, integrar, transferir conhecimentos, recursos, habilidades que agreguem valor econômico à organização e valor social aos indivíduos.

O conceito de competência comumente encontrado na literatura é abordado como sendo a entrega e as características da pessoa que pode entregar-se à organização. A definição de entrega, nesse ponto, refere-se ao esforço e à dedicação que a pessoa pode despender à empresa. Assim, Munck, Munck e Souza (2011) afirmam que o fato de uma pessoa deter um conjunto de conhecimentos, habilidades e atitudes não implica necessariamente que a organização se beneficie diretamente deles, visto que há necessidade de haver a entrega desses em benefício da organização.

A discussão de temas como ética, valores, poder, controle e emancipação promove modificações e reflexões sobre a finalidade do desenvolvimento de competências, questionando, em última instância, seu sentido e sua finalidade na busca do entendimento de seu sentido (CARVALHO, STEFANO e MUNCK, 2015). O interesse é reposicionar a discussão sobre competências, ampliando para aspectos que não eram questionados nas pesquisas e nos estudos que abordam a gestão, reconhecendo a ação humana, o fazer, a materialização de decisões e processos, assim como a forma como eles intervêm no trabalho e no mundo.

O papel de estabelecer meios de concretização das ações estratégicas passa pela atuação do departamento de recursos humanos, o qual toma para si a responsabilidade de alinhar anseios organizacionais e pretensões individuais. A gestão de recursos humanos, quando orientada por competências, deve concentrar-se primeiramente nas pessoas e, posteriormente, em seus resultados. As competências são simultaneamente legítimas e confiáveis na diferenciação entre funcionários exemplares e trabalhadores com sucesso diferenciado. É de fundamental importância a consistência da estratégia organizacional para a efetividade de todos esses processos (DUBOIS e ROTHWELL, 2004).

Ao tratar da administração das competências dos indivíduos direcionadas para a realização dos objetivos organizacionais focados na sustentabilidade, a organização precisa observar os colaboradores que nela exercem suas funções de forma diferenciada, não como um recurso ou um ativo, mas como uma extensão estratégica de todos os objetivos mercadológicos. Assim, as competências individuais evidenciam a propensão dos trabalhadores em tomar decisões acertadas diante de situações de complexidade elevada. No processo de fomentar as competências individuais como um instrumento de estímulo 
ao desenvolvimento, a empresa se empenhará em promover um planejamento que estabeleça como requisito a prática da sustentabilidade, sendo uma ferramenta de emancipação de competências organizacionais (MUNCK, SOUZA e SAGUI, 2011).

Nesse contexto, Brunstein e Boulos (2009) asseveram que as competências interligam o colaborador à empresa por meio de uma estreita compreensão sistemática e contributiva, que produz e alimenta a si mesma. Cada personagem engajado nesse processo estabelece um compromisso social conjunto, pelo qual todos os envolvidos necessitam assumir e desempenhar seus papéis no desenvolvimento empresarial, amparados por premissas responsáveis. A valorização do ser humano por trás do profissional, como agente fundamental para a promoção de mudanças, estimula a transformação da organização em um ambiente receptivo, aberto à adaptação e ao compartilhamento de responsabilidades.

A gestão das competências organizacionais, portanto, pode ser compreendida como uma resposta aos anseios sociais por ações organizacionais voltadas para a sustentabilidade. Ao aproximar os objetivos de indivíduos e empresas, o desenvolvimento das competências propicia a formação de um ambiente de debate sobre as problemáticas da organização, tanto as relacionadas com as responsabilidades econômicas quanto as sociais e ambientais. Assim, o diálogo estabelecido entre o desenvolvimento de competências e ações em sustentabilidade organizacional demanda conhecimentos interdisciplinares e pluralistas, pois o ambiente organizacional e os anseios pessoais não podem mais ser compreendidos senão por meio de sua complexidade.

\section{SUSTENTABILIDADE NAS ORGANIZAÇÕES}

As organizações envolvidas ativamente no debate sobre a sustentabilidade buscam constantemente identificar maneiras pelas quais possam desenvolver novas formas de produção e de gestão de recursos que confluam para o aprimoramento de práticas relacionadas com cada um dos pilares que a fundamentam. É necessário reconhecer que o comportamento das organizações, refletindo as demandas de movimentos internos e externos ao ambiente empresarial, suscita o reposicionamento e a reconsideração de atitudes e comportamentos. Tais atitudes procuram estar inseridas no posicionamento estratégico que direciona o comportamento socioeconômico dessas empresas, motivo pelo qual a sucessão de mudanças, na busca de alinhamento com os anseios da sociedade, governo e demais entidades, se torna um desafio na busca de um desenvolvimento sustentável (MUNCK e SOUZA, 2009). Assim, as organizações se empenham em aprimorar suas práticas de gestão em caminhos estratégicos que as auxiliam a oferecer respostas a tais demandas.

O envolvimento das organizações em problemáticas de cunho socioambiental pode transformar-se em uma oportunidade de negócios, contribuindo para a melhoria de qualidade de vida dos stakeholders e a sustentabilidade dos recursos naturais. Para Claro, Claro e Amâncio (2008), a preocupação de muitas organizações com o problema da poluição, por exemplo, tem feito com que elas reavaliem o processo produtivo, buscando a obtenção de tecnologias limpas e o reaproveitamento dos resíduos. Isso gera grandes economias de recursos, que não seriam viabilizadas se elas não tivessem tratado dessa situação. Os benefícios econômicos podem resultar de economia de custos ou incremento de receitas. Os benefícios estratégicos resultam de melhoria da imagem institucional, renovação da carteira de produtos, aumento da produtividade, alto comprometimento do pessoal, melhoria nas relações de trabalho, melhoria da criatividade para novos desafios e melhoria das relações com os órgãos governamentais, comunidade e grupos ambientalistas.

Com o intuito de compreender o desenvolvimento sustentável de organizações produtivas, Savitz e Weber (2007) conceituam essa expressão como a busca de um equilíbrio entre o que é socialmente desejável, economicamente viável e ambientalmente sustentável. A organização sustentável seria aquela que consegue, efetivamente, gerar lucro para proprietários e acionistas, protege o meio ambiente e melhora a vida das pessoas com as quais mantém interações (LÉON-SORIANO, MUNÕZ-TORRES e CHALMETA-ROSALEN, 2010). Ainda de acordo com os autores, a sustentabilidade organizacional pode ser tomada como a capacidade de as organizações alavancarem seu capital econômico, social e ambiental a fim de contribuir para o desenvolvimento sustentável em seu domínio político.

As ações organizacionais sustentáveis são, conforme argumentação de Munck e Souza (2009), as que causam o menor impacto ambiental possível por meio de atividades operacionais preocupadas em simultaneamente promover um desenvolvimento socioeconômico que propicie a sobrevivência das gerações presentes e futuras. A implicação do fomento a esse 
desenvolvimento, segundo os autores, deve dar-se de maneira articulada com os indivíduos inseridos em ambientes sociais e organizacionais, uma vez que é por meio deles que são estabelecidas as decisões finais validadoras de todas essas proposições.

Assim, objetivando que uma organização se torne realmente sustentável, é necessário que haja integração de ações com foco nos aspectos econômico, social e ambiental, os quais compõem um constructo maior, que é a sustentabilidade organizacional. A concepção baseada nos três aspectos fundamentais do ser sustentável assegura tanto o crescimento econômico quanto a atenção à qualidade ambiental e à justiça social (JAMALI, 2006). Aproximando, portanto, a sustentabilidade do contexto empresarial, busca-se compreender e criar meios de promover a sustentabilidade econômica, ao mesmo tempo que há preocupação com as dimensões da eficiência social e da justiça ambiental. Nesse ponto, a sustentabilidade organizacional assume um caráter complexo, podendo ser segmentada na sustentabilidade organizacional econômica, sustentabilidade organizacional ambiental e sustentabilidade organizacional social (CALLADO, 2010).

A sustentabilidade econômica, conforme afirmam Lorenzetti, Cruz e Ricioli (2008), diz respeito à atuação da empresa, influenciando as condições econômicas, o sistema econômico em seus diversos níveis, a geração de riquezas para a sociedade e o fornecimento de bens e serviços. A viabilidade econômica é o argumento central do desenvolvimento sustentável, uma vez que é por meio da circulação de riquezas e da geração de lucros que são providos os empregos e proporciona-se à comunidade a possibilidade de melhoria de suas condições de vida (AUTIO, KENNEY, MUSTAR et al., 2014). Os autores atestam que a sustentabilidade econômica de uma organização mensura a capacidade de desenvolver suas atividades de maneira responsável, com lucratividade suficientemente atrativa para proprietários e investidores.

A sustentabilidade ambiental refere-se ao uso racional dos recursos naturais, como energia e materiais, bem como à preservação e à recomposição dos espaços naturais (fauna, flora e recursos hídricos) (KRAJNC e GLAVIC, 2005). Faz-se indispensável que a organização, sob a perspectiva dos impactos de suas operações e produtos sobre os sistemas naturais vivos e não vivos, objetive reduzir os impactos negativos e amplificar os positivos, desenvolvendo tecnologias com o intuito de melhorar o desempenho de produção, ao mesmo tempo que se preservam os recursos naturais. Portanto, a responsabilidade sobre o espaço natural compreende preocupações além do simples cumprimento da lei, ou iniciativas como reciclagem ou uso eficiente de recursos energéticos, envolvendo um tratamento que, efetivamente modifique as operações organizacionais (PETRINI e POZZEBON, 2010).

A sustentabilidade social remete ao estímulo da igualdade e à participação de todos os grupos sociais na construção e manutenção do equilíbrio do sistema, compartilhando direitos e responsabilidades (GREENWOOD, 2007). O aspecto social, para as empresas, refere-se a seu impacto na sociedade, comunidade local e entornos em que operam, sendo o desempenho social abordado por meio dessa análise, considerando os diversos níveis de alcance como local, nacional e global. Para Krajnc e Glavic (2005), o aspecto social da sustentabilidade, se analisado sob o prisma das empresas, refere-se às atitudes organizacionais em relação aos próprios colaboradores, fornecedores, contratados e consumidores, além de impactos na sociedade em geral, para além de seus domínios.

Os três aspectos da sustentabilidade organizacional (social, ambiental e econômica) devem ser trabalhados de forma conjunta, objetivando o alcance de uma instância maior e mais complexa, que é o desenvolvimento sustentável (CALLADO, 2010). Assim, aponta-se que, em um contexto no qual se busca o equilíbrio sistêmico entre as dimensões da sustentabilidade, é indispensável compreender a urgência em fazer uso dos recursos que a natureza oferece para garantir às gerações futuras uma sociedade de prosperidade e justiça, com melhor qualidade ambiental e de vida.

\section{COMPETÊNCIAS PARA A SUSTENTABILIDADE ORGANIZACIONAL}

A relação entre a geração de competências societais e a sustentabilidade, aplicada ao contexto das organizações, é explorada pela literatura, a qual trata da temática por meio de estudos que compreendem várias formas de interpretação e de condução de pesquisas. Desse modo, podem-se definir competências para a sustentabilidade como aquelas que são capazes de desenvolver e/ou manter processos participativos efetivos, estruturas de governança empoderadoras e incentivar e promover ciclos de feedback que institucionalizem mudanças (BRUNSTEIN e BOULOS, 2009). Entretanto, os autores atentam para 
o fato de que, no desenvolvimento das atividades organizacionais, o termo se "tecniciza", se despolitiza, se esvazia e se distancia de discussões sobre relações de poder complexas.

A competência, gerada no contexto da atividade de trabalho desenvolvida por indivíduos ou grupos de indivíduos, não pode ser comparada com um ativo físico, devendo ser entendida como um conjunto integrado de habilidades e tecnologias que resultam em um diferencial competitivo para a empresa (HANSEN, PERRY e REESE, 2004). Isso exige comunicação, envolvimento e comprometimento organizacional, pois envolve diversos níveis e funções. Conforme essa concepção, Hunt e Morgan (1995) asseveram que a empresa necessita identificar o que sabe fazer melhor, aquilo que não é facilmente imitado, algo que pertença ao conhecimento implícito da organização, que aumente com a aplicação e compartilhamento. As competências devem ser desenvolvidas ao longo de muitos anos, de forma orientada, por meio de um arranjo que permita ampliar e integrar os recursos internos, a fim de acumular um amplo conjunto de competências que formem a competência essencial.

No mesmo sentido de entendimento, o relatório do World Business Council for Sustainable Development (WBCSD, Conselho Empresarial Mundial para o Desenvolvimento Sustentável) (2008), enfatiza que o que promove o avanço de competências para a sustentabilidade é o conhecimento produzido nas organizações na tentativa de inclusão das necessidades e das aspirações de diferentes grupos de interesse, bem como na promoção do equilíbrio e do reconhecimento de direitos. Essas proposições foram estabelecidas por um relatório, formalizado no documento intitulado Driving success: human resources and sustainable development, cujo propósito foi nortear a inserção do tema sustentabilidade em gestão de pessoas nas organizações. Esse relatório define um modelo de competências básicas necessárias para que as pessoas possam efetivamente desenvolver sua visão sobre a importância da sustentabilidade. São apontados três eixos principais que norteiam e sustentam o modelo: estratégia, grupos de interesse (stakeholders) e liderança, ou seja, planejar, relacionar-se e empreender mudanças. O que dá suporte às competências é o conhecimento que se produz no processo de interação e experimentação contínua, que inclui aspirações de diferentes grupos de interesse na tentativa de promover equilíbrio e reconhecimento de direitos.

Corroborando, Fleury e Fleury (2005) estabelecem um entendimento a respeito de competência, propondo um conceito que o aproxima dos preceitos da sustentabilidade, defendendo que a competência societal é um saber agir responsável e reconhecido, que implica mobilizar, integrar e transferir conhecimentos, recursos e habilidades que agreguem valor econômico à organização e valor social ao indivíduo. As habilidades do colaborador são colocadas a serviço da realização dos objetivos organizacionais, confluindo os interesses da organização com os dos indivíduos que a compõem.

Os autores ainda asseveram que a demanda por um posicionamento pautado pela responsabilidade no desenvolvimento de ações e que a agregação de valor social ao indivíduo implicam torná-lo autônomo em relação às consequências de suas decisões e escolhas. Dispor das habilidades individuais como instrumento de melhoria do desempenho no trabalho auxilia no emprego das qualificações do trabalhador, que são utilizadas como elemento de realização dos objetivos e das metas organizacionais. Os diversos relatórios de órgãos governamentais e não governamentais internacionais indicam que os vários desafios organizacionais e sociais mundiais não são compreendidos em grande parte pela falta de competência. Portanto, indivíduos, equipes e organizações competentes são capazes de gerar alto valor para a sociedade (FLEURY e FLEURY, 2004).

A pesquisa desenvolvida por Wilson, Lenssen e Hind (2006), que versa sobre o tema em discussão, aborda líderes formais de organizações de ponta, como IBM, Johnson \& Johnson, Microsoft, Shell e Unilever, explorando a tomada de decisão dos líderes e suas relações com questões sociais e ambientais. O objetivo do estudo foi, de forma abrangente, discutir maneiras de desenvolver gerentes com conhecimentos, habilidades e competências suficientemente relevantes para atender às demandas de concorrência das organizações contemporâneas. Os resultados direcionam para as seguintes competências como sendo importantes para o avanço da sustentabilidade nas organizações:

a) Competência para entender a interdependência entre empresas e a sociedade - que requer uma profunda compreensão das relações organizacionais internas e das dinâmicas sociais, econômicas, ambientais e culturais externas. Dos gestores, esperam-se a mudança estratégica chave na forma como veem o mundo (reconhecer que a empresa não está operando em um sistema fechado) e a capacidade de interpretar os sinais emitidos pelos atores que interagem com a organização e com o mercado, apresentando respostas apropriadas.

b) Competência para lidar com a diversidade - que significa construir equipes de trabalho compostas por membros que reflitam a diversidade presente na sociedade na qual as organizações operam. 
c) Competência de manter um diálogo significativo com os diferentes grupos de interesse da organização - que representa desenvolver canais de escuta efetiva, fato que implica que o gestor caminhe de um processo de tomada de decisão em que decide, comunica e defende sua posição para o diálogo e a decisão conjunta. Esse processo pode ser descrito como um método mais compreensivo de engajamento com os stakeholders.

O conceito de competência organizacional que a referida pesquisa define converge para as proposições inseridas na compreensão das temáticas da sustentabilidade e da responsabilidade social empresarial. Trata-se da capacidade de lidar com os impactos sociais e ambientais da gestão das organizações em múltiplos grupos de interesse e estabelecer diálogos entre empresas e sociedade em direção à construção de uma forma diferenciada de gestão (WILSON, LENSSEN e HIND, 2006).

Para Almeida (2007), a composição do estudo das competências voltadas à sustentabilidade requer a compreensão de que, em suma, a sustentabilidade aplicada em um ambiente empresarial leva, invariavelmente, à subversão dos modelos de gestão e de condução dos negócios. Ao defender esse pensamento, o autor afirma, categoricamente, que a ordem e os conceitos instalados são sacudidos, redefinindo as estruturas de poder. Além de exigir o equilíbrio de objetivos econômicos, ambientais e sociais, operar na sustentabilidade implica atuar em um mundo tripolar, em que o poder tende a se repartir, de maneira cada vez mais equilibrada, entre governos, empresas e organizações da sociedade civil, uma vez que as demandas e os anseios desses públicos são considerados importantes e influentes no processo de tomada de decisões.

A adaptação da forma como as situações são conduzidas implica a flexibilização do agir e das decisões empresariais, de modo que se compreenda a sustentabilidade não apenas como um discurso sobre ecologia e economia, mas essencialmente como uma discussão de cunho ideológico e político. Ela necessariamente demanda um processo de investigação crítica, considerando as forças econômicas, políticas, sociais, culturais, tecnológicas e ambientais que a nutrem ou a impedem (SPRINGETT, 2005). Portanto, reconhecendo a importância da aprendizagem como forma de geração de competências, assevera-se que o discurso de educação/desenvolvimento para a sustentabilidade se fundamenta na crença de que ele tem o poder de guiar as pessoas para refletir e agir de acordo com uma perspectiva política, crítica e emancipatória que tende a romper com a forma clássica e ideologicamente dominante com que os negócios são conduzidos (SPRINGETT, 2005).

Logo, a capacitação e a educação para a sustentabilidade são um ponto que converge para a confrontação de interesses e para a tensão das estruturas de poder e dos modos tradicionais de se fazer organização, uma vez que desafia a racionalidade do paradigma capitalista da produção e do consumo e, nesse sentido, estabelece um desafio às empresas (CARVALHO e BARBIERI, 2010). Para Springett (2005), quando se trata de educação para a sustentabilidade, o foco deve sair do "o quê" para o "como" desenvolver estratégias de gestão socioeconômica-ambiental, transformando os discursos voltados ao "que os negócios devem fazer" para aqueles que questionam "o que os negócios devem ser".

Entretanto, a complexidade que envolve a mudança organizacional, conforme destacam Kleef e Roome (2007), é dada pelos diferentes estilos e culturas gerenciais e pode ser incompatível com demandas socioambientais, da mesma forma que os acordos entre organizações não governamentais (ONGs) e empresas podem se revelar fracos e conflituosos. A busca do distanciamento e da minimização de riscos pode enfraquecer ou tornar menos atrativa a inclusão de novos parceiros, assim como pode haver falta de habilidade para facilitar um processo de aprendizagem envolvendo múltiplos atores.

O entendimento do processo de desenvolvimento de competências para a inovação, orientada pelo direcionamento e foco em ações de sustentabilidade nas organizações, de acordo com Kleef e Roome (2007), envolve as seguintes competências, consideradas pelos autores como fundamentais:

a) pensamento sistêmico;

b) capacidade de aprender e transformar a aprendizagem em ação, de modo a lidar efetivamente com exigências, valores, pressupostos e culturas dos diferentes atores que interagem em networks, visando a compreender e a executar com sucesso as ações inovadoras em rede;

c) capacidade de integrar negócios, ambiente e problemas sociais, perspectivas e informações, isto é, saber integrar perspectivas e conhecimentos de diferentes atores em rede, bem como critérios tradicionais de eficiência com eco e socioeficiência;

d) capacidade de desenvolver modelos de negócios alternativos, métodos e trajetórias dinâmicas e pragmáticas para promover inovação radical ou sistêmica; 
e) capacidade de desenvolver relações sociais com atores não familiares culturalmente, dentro e fora da organização, com o propósito de juntar informação, promover a experimentação e a negociação, além de criar e cultivar amplamente networks diversos que permitam juntar informações dos atores da rede para lidar com a incerteza;

f) capacidade de formar coalizões e colaborar: promover a ação conjunta de diferentes stakeholders (locais), ter abertura para o processo de inovação e adaptação, adotar uma visão compartilhada, apoiar a elaboração de soluções de problemas coletivamente, integrar as diferenças em processamento de informações e estilos de decisão, lidar com as diferenças de foco, ter consenso e maximizar resultados.

A sustentabilidade organizacional pode ser desenvolvida, também, mediante as competências individuais sob a ótica do saber agir, assumir responsabilidades e ter iniciativa (DUTRA, 2012; FLEURY e FLEURY, 2004). A competência voltada para a sustentabilidade deve agregar valor à organização, ao indivíduo, à sociedade e ao meio ambiente. Entretanto, estudos sobre competências individuais ou coletivas voltadas à sustentabilidade ainda não são muito numerosos, embora pesquisas recentes tenham tratado da temática.

A pesquisa de Wiek, Withycombe e Redman (2011), de cunho bibliográfico, resultou em uma profunda revisão com as sínteses das principais contribuições da literatura sobre o tema. O Quadro 1 apresenta um resumo detalhado das competências para a sustentabilidade apontadas pelos autores, evidenciando suas principais características e definições.

\section{Quadro 1}

\section{Competências para a sustentabilidade e características}

\begin{tabular}{|c|c|}
\hline $\begin{array}{l}\text { Competência para a } \\
\text { sustentabilidade }\end{array}$ & Definição/característica \\
\hline $\begin{array}{l}\text { Foco em pensamento } \\
\text { sistêmico }\end{array}$ & $\begin{array}{l}\text { Capacidade de analisar coletivamente sistemas complexos em diferentes domínios (sociedade, } \\
\text { meio ambiente, economia etc.) e em diferentes escalas (local a global), considerando-se, assim, } \\
\text { feedback e outras recursos relacionados com questões de sustentabilidade e quadros de resolução } \\
\text { de problemas sustentáveis. A capacidade de analisar sistemas complexos inclui compreender e } \\
\text { verificar empiricamente, articulando sua estrutura, os principais componentes e sua dinâmica. A } \\
\text { capacidade de analisar se baseia no conhecimento sistêmico adquirido, incluindo conceitos como } \\
\text { estrutura, função, relações de causa e efeito, mas também percepções, decisões e regulamentos. }\end{array}$ \\
\hline Preventiva & $\begin{array}{l}\text { Capacidade de, coletivamente, analisar e avaliar o cenário futuro relacionado com questões de } \\
\text { sustentabilidade e de cenários de resolução de problemas de sustentabilidade. A capacidade de } \\
\text { analisar cenários futuros inclui ser capaz de compreender e articular sua estrutura; a capacidade } \\
\text { de avaliar se refere às habilidades comparativas que se relacionam com o "estado da arte"; } \\
\text { finalmente, a capacidade de criar integra habilidades criativas e construtivas. }\end{array}$ \\
\hline Normativa & $\begin{array}{l}\text { Capacidade de especificar, aplicar, conciliar e negociar valores de sustentabilidade, princípios, } \\
\text { objetivos e metas. Essa capacidade permite, primeiro, avaliar coletivamente a sustentabilidade } \\
\text { dos estados atuais e/ou futuros de sistemas organizacionais e, em seguida, criar coletivamente as } \\
\text { visões de sustentabilidade para esses sistemas. Baseia-se no conhecimento adquirido normativo, } \\
\text { incluindo conceitos de justiça, equidade, integridade socioecológica e ética. Essas habilidades são } \\
\text { adaptadas para abordar questões-chave da sustentabilidade socioecológica, incluindo integridade, } \\
\text { sistemas lógicos e equidade organizacional. }\end{array}$ \\
\hline Estratégica & $\begin{array}{l}\text { Capacidade de implementar intervenções, transições e estratégias de governança de transformação } \\
\text { em direção à sustentabilidade. Essa capacidade requer uma compreensão profunda de conceitos } \\
\text { estratégicos, como intencionalidade, inércia sistêmica, dependências de caminho, barreiras, } \\
\text { transportadoras, alianças etc.; conhecimento sobre viabilidade, eficácia, eficiência de intervenções } \\
\text { sistêmicas, bem como o potencial de consequências não intencionais etc. }\end{array}$ \\
\hline Interpessoal & $\begin{array}{l}\text { Capacidade de motivar, possibilitar e facilitar a colaboração e a pesquisa sobre sustentabilidade } \\
\text { participativa e resolução de problemas. Inclui habilidades avançadas na comunicação, tomada } \\
\text { de decisão e de negociação, colaboração, liderança, pluralista e pensamento cultural, e empatia. } \\
\text { A capacidade de compreender, aceitar e fomentar a diversidade entre culturas, grupos sociais, } \\
\text { comunidades e indivíduos é reconhecida como um componente-chave dessa competência. }\end{array}$ \\
\hline
\end{tabular}

Fonte: Adaptado de Wiek, Withycombe e Redman (2011). 
As competências são consideradas como de suporte ou primárias ao atingimento da sustentabilidade organizacional. Os resultados individuais, fruto dos desempenhos dos colaboradores, se traduzem em ações para a sustentabilidade (WIEK, WITHYCOMBE e REDMAN, 2011). Para que uma empresa possa alcançar desenvolvimento pleno, no sentido da sustentabilidade organizacional, seus gestores e colaboradores devem ter competências e entregas específicas para esse fim, com o intuito de conduzir os demais indivíduos rumo aos objetivos organizacionais.

\section{PROCEDIMENTOS METODOLÓGICOS}

\section{Objetivo e descrição da metodologia}

A presente pesquisa buscou explorar a relação entre competências organizacionais e a sustentabilidade organizacional, estabelecendo uma análise embasada em estudos que tratam de competências societais relacionadas com a sustentabilidade.

Desse modo, a obtenção de informações e variáveis sobre a temática central foi realizada por meio de análise sistemática, ou seja, uma revisão a partir de uma busca planejada com o intuito de responder ao objetivo proposto e que utiliza métodos explícitos e sistemáticos para identificar, selecionar, coletar e avaliar criticamente os estudos incluídos na revisão (CASTRO, 2001).

\section{UNIVERSO E AMOSTRA DA PESQUISA}

Com o intuito de investigar a relação estabelecida entre competências societais e sustentabilidade aplicada ao contexto das organizações, buscou-se identificar artigos acadêmicos científicos publicados entre 2010 e 2015. Utilizou-se a produção científica nos principais eventos dentro do campo das ciências administrativas, contábeis e afins a partir de buscas no Portal de Periódicos da Capes e na base de dados da Anpad.

A seleção dos artigos teve início com a determinação das palavras-chave, ou seja, as possíveis combinações que atendessem ao objetivo da pesquisa. Os artigos, com base nas palavras-chave, foram selecionados nos seguintes eventos e revistas: Encontro da Anpad (EnANPAD), Encontro de Gestão, Pessoas e Relações de Trabalho (EnGPR), Revista Produção, Revista Pretexto e Revista Gestão e Conexões.

Os descritores utilizados na busca foram "Competência" na combinação "and" com o termo "Sustentabilidade", "Competências societais" na combinação "and" com o termo "Sustentabilidade", e "Sustainability" na combinação "and" com o termo "Skills". Foram localizados 59 artigos na base de dados do Portal de Periódicos da Capes, na soma das combinações, e 162 artigos nas combinações da base de dados da Anpad. Após a leitura dos títulos e dos resumos dos artigos, foram filtrados 32 para análise dos conteúdos, buscando enquadrá-los conforme o objetivo proposto.

Diante do exposto, o próximo passo da coleta de dados foi selecionar os artigos conforme os critérios de inclusão e exclusão estabelecidos:

a) Em relação ao conteúdo: foram incluídos os artigos que apresentaram a temática central correlacionados com as competências organizacionais e a formação de ações com foco em sustentabilidade organizacional, empreendidos no período entre 2010 e 2015.

b) Em relação ao tipo de artigo: foram considerados os artigos com metodologias qualitativa e quantitativa das diversas áreas da administração, ciências contábeis e economia.

c) Em relação à língua: foram considerados somente artigos em português, visto que não se encontraram publicações sobre o tema em demais línguas estabelecidas (inglês e espanhol). 
d) Critérios de exclusão: foram excluídos os artigos que tratavam da geração de competências organizacionais não relacionadas com a prática de sustentabilidade; os que abordam temas muito específicos dentro da temática sustentabilidade; que integram o desenvolvimento sustentável ou práticas de responsabilidade social corporativa; e que trabalham com a sustentabilidade fora do ambiente organizacional de empresas produtivas.

Após critérios de seleção, chegou-se a oito artigos, demonstrados no Quadro 2.

\section{Quadro 2}

\section{Relação de artigos selecionados conforme os descritores}

\begin{tabular}{|c|c|c|c|c|c|}
\hline \multirow{2}{*}{ Busca } & \multirow{2}{*}{$\begin{array}{c}\text { Ano de } \\
\text { publicação }\end{array}$} & \begin{tabular}{c} 
Combinações \\
"Competência" e \\
\cline { 3 - 6 }
\end{tabular} & $\begin{array}{c}\text { "Competências } \\
\text { societais" e } \\
\text { "Sustentabilidade" }\end{array}$ & $\begin{array}{c}\text { "Skills" e } \\
\text { "Sustainability" }\end{array}$ \\
\hline Anpad & $2010-2015$ & 4 & 1 & - & - \\
\hline Capes & $2010-2015$ & 1 & 2 & - \\
\hline \multicolumn{2}{|c|}{ Total } & 5 & 3 & 8 \\
\hline
\end{tabular}

Fonte: Dados da pesquisa (2016).

A leitura da revisão bibliográfica foi utilizada para o embasamento teórico desta pesquisa, bem como livros e demais pesquisas (artigos, teses e dissertações). Já a revisão dos resultados e demais variáveis foram utilizadas para a análise qualitativa deste.

\section{APRESENTAÇÃO E DISCUSSÃO DOS RESULTADOS}

Conforme o objetivo proposto e a metodologia de pesquisa utilizada, foram selecwionados oito estudos relevantes e em conformidade com a problemática abordada. Todos eles buscam explorar a relação estabelecida entre a geração de competências organizacionais de colaboradores ou gerentes e a sustentabilidade aplicada ao ambiente empresarial. Ressalta-se, portanto, que as competências supracitadas referem-se tanto a colaboradores quanto a gerentes, sempre objetivando a instrumentalização de habilidades colocadas a serviço da empresa. Assim, a sustentabilidade de que trata a proposta de pesquisa diz respeito, invariavelmente, à modalidade aplicada às empresas.

Os estudos selecionados são apresentados detalhadamente no Quadro 3. 
Quadro 3

Apresentação dos estudos selecionados conforme a proposta metodológica

\begin{tabular}{|c|c|c|c|c|c|}
\hline Autor & Título do artigo & Objetivo de pesquisa & Metodologia & $\begin{array}{c}\text { Modelo teórico de } \\
\text { suporte }\end{array}$ & Resultados \\
\hline $\begin{array}{l}\text { BRUNSTEIN, } \\
\text { SCARTEZINI e } \\
\text { RODRIGUES } \\
(2010)\end{array}$ & $\begin{array}{l}\text { Competência } \\
\text { societal: uma } \\
\text { experiência } \\
\text { corporativa de } \\
\text { ação educativa } \\
\text { Itada ao } \\
\text { desenvolvimento } \\
\text { de gestores para } \\
\text { sustentabilidade }\end{array}$ & $\begin{array}{l}\text { Discutir o conceito } \\
\text { de competência } \\
\text { societal, sobretudo } \\
\text { no desenvolvimento } \\
\text { de pessoas com foco } \\
\text { em sustentabilidade, } \\
\text { e empreender } \\
\text { uma análise das } \\
\text { competências } \\
\text { de gestores } \\
\text { em questões } \\
\text { relacionadas com a } \\
\text { sustentabilidade }\end{array}$ & $\begin{array}{l}\text { Estudo de caso } \\
\text { qualitativo, } \\
\text { com aplicação } \\
\text { de entrevistas, } \\
\text { análise } \\
\text { documental e } \\
\text { observação }\end{array}$ & $\begin{array}{l}\text { Concepção } \\
\text { interpretativista de } \\
\text { competências: Ruth } \\
\text { (2006) e Sandberg } \\
\text { (2000; 2006) } \\
\text { Sustentabilidade e } \\
\text { desenvolvimento de } \\
\text { pessoas: Springett } \\
\text { (2005) e Kleef e } \\
\text { Roome (2007) }\end{array}$ & $\begin{array}{l}\text { O discurso dos gestores se tornou } \\
\text { competente, mas a ação nem } \\
\text { sempre chega ao mesmo patamar } \\
\text { de excelência. Os colaboradores } \\
\text { adquiriram conhecimento e visão } \\
\text { crítica, mas ainda enfrentam } \\
\text { dificuldades para harmonizar } \\
\text { os objetivos do negócio com os } \\
\text { princípios da sustentabilidade. } \\
\text { Mesmo com formação } \\
\text { avançada, os paradoxos da ação } \\
\text { permanecem }\end{array}$ \\
\hline $\begin{array}{l}\text { BRUNSTEIN e } \\
\text { RODRIGUES } \\
(2011)\end{array}$ & $\begin{array}{l}\text { Sustentabilidade, } \\
\text { sentido e ação: } \\
\text { contribuições } \\
\text { para o } \\
\text { desenvolvimento } \\
\text { da competência } \\
\text { societal }\end{array}$ & $\begin{array}{l}\text { Analisar uma } \\
\text { iniciativa de } \\
\text { desenvolvimento } \\
\text { de gestores para a } \\
\text { sustentabilidade em } \\
\text { uma empresa cuja } \\
\text { visão estratégica é } \\
\text { tornar-se referência } \\
\text { em soluções } \\
\text { ambientais }\end{array}$ & $\begin{array}{l}\text { Qualitativa, } \\
\text { com } \\
\text { abordagem } \\
\text { interpretivista }\end{array}$ & $\begin{array}{l}\text { Competências } \\
\text { societais: Holland, } \\
\text { Ritvo e Kovner (1997) } \\
\text { Diálogos reflexivos } \\
\text { e competências } \\
\text { societais: Sandberg e } \\
\text { Dall'Alba (2006) }\end{array}$ & $\begin{array}{l}\text { A sustentabilidade se } \\
\text { instaurou como quimera, e sua } \\
\text { operacionalização ainda está } \\
\text { envolta em dúvidas, paradoxos } \\
\text { e dilemas. O desenvolvimento } \\
\text { de competências societais por } \\
\text { parte dos gestores é algo em } \\
\text { andamento }\end{array}$ \\
\hline $\begin{array}{l}\text { DEMAJOROVIC } \\
\text { e MARTÃO } \\
(2014)\end{array}$ & $\begin{array}{l}\text { Competências } \\
\text { e inserção } \\
\text { profissional de } \\
\text { administradores } \\
\text { em } \\
\text { sustentabilidade }\end{array}$ & $\begin{array}{l}\text { Avaliar como práticas } \\
\text { interdisciplinares } \\
\text { em cursos de } \\
\text { administração } \\
\text { contribuem para o } \\
\text { desenvolvimento de } \\
\text { competências para a } \\
\text { sustentabilidade }\end{array}$ & $\begin{array}{l}\text { Qualitativa, } \\
\text { com aplicação } \\
\text { de entrevistas } \\
\text { semiestru- } \\
\text { turadas }\end{array}$ & $\begin{array}{l}\text { Competências para a } \\
\text { sustentabilidade ou } \\
\text { "Ges/taltungskom- } \\
\text { petenz": Haan (2006) } \\
\text { e Shrivastana (2010) }\end{array}$ & $\begin{array}{l}\text { Práticas interdisciplinares } \\
\text { contribuem para o } \\
\text { desenvolvimento de } \\
\text { competências para a } \\
\text { sustentabilidade como visão } \\
\text { sistêmica, pensamento crítico, } \\
\text { diálogo com diferentes atores } \\
\text { e comprometimento pessoal. A } \\
\text { falta de entendimento por parte } \\
\text { dos gestores de mercado dificulta } \\
\text { a inserção de administradores na } \\
\text { gestão da sustentabilidade nas } \\
\text { organizações }\end{array}$ \\
\hline $\begin{array}{l}\text { MUNCK, } \\
\text { GALLELI } \\
\text { e SOUZA } \\
(2013)\end{array}$ & $\begin{array}{l}\text { Competências } \\
\text { para a } \\
\text { sustentabilidade } \\
\text { organizacional: } \\
\text { a proposição de } \\
\text { um framework } \\
\text { representativo do } \\
\text { acontecimento } \\
\text { da ecoeficiência }\end{array}$ & $\begin{array}{l}\text { Propor um } \\
\text { framework } \\
\text { representativo do } \\
\text { acontecimento } \\
\text { da ecoeficiência } \\
\text { organizacional pela } \\
\text { via da competência } \\
\text { que indique o } \\
\text { potencial de ser } \\
\text { ecoeficiente das } \\
\text { organizações, a } \\
\text { partir da avaliação } \\
\text { de entregas de suas } \\
\text { competências }\end{array}$ & $\begin{array}{l}\text { Qualitativa, } \\
\text { exploratória e } \\
\text { bibliográfica }\end{array}$ & $\begin{array}{l}\text { Dimensões da } \\
\text { ecoeficiência: World } \\
\text { Business Council } \\
\text { for Sustainable } \\
\text { Development (2000) }\end{array}$ & $\begin{array}{l}\text { A gestão por competências } \\
\text { é uma alternativa concreta } \\
\text { para compreender e integrar } \\
\text { a rede que permitirá respostas } \\
\text { aos anseios sociais por ações } \\
\text { organizacionais voltadas } \\
\text { para a sustentabilidade. A } \\
\text { gestão por competências } \\
\text { converge diretamente com a } \\
\text { operacionalização em meio } \\
\text { organizacional da proposta } \\
\text { interativa do Triple Bottom Line } \\
\text { a partir da ecoeficiência }\end{array}$ \\
\hline
\end{tabular}


Continuação

\begin{tabular}{|c|c|c|c|c|c|}
\hline Autor & Título do artigo & Objetivo de pesquisa & Metodologia & $\begin{array}{l}\text { Modelo teórico de } \\
\text { suporte }\end{array}$ & Resultados \\
\hline $\begin{array}{l}\text { MUNCK, } \\
\text { MUNCK } \\
\text { e SOUZA } \\
(2011)\end{array}$ & $\begin{array}{l}\text { Sustentabilidade } \\
\text { organizacional: } \\
\text { a proposição de } \\
\text { um framework } \\
\text { representativa do } \\
\text { agir competente } \\
\text { para seu } \\
\text { acontecimento }\end{array}$ & $\begin{array}{l}\text { Propor um } \\
\text { framework } \\
\text { representativa } \\
\text { dos processos } \\
\text { necessários ao } \\
\text { acontecimento da } \\
\text { sustentabilidade } \\
\text { organizacional. }\end{array}$ & $\begin{array}{l}\text { Qualitativa, } \\
\text { teórica, } \\
\text { exploratória e } \\
\text { bibliográfica }\end{array}$ & $\begin{array}{l}\text { Teoria do Agir } \\
\text { Organizacional: } \\
\text { Maggi (2003) }\end{array}$ & $\begin{array}{l}\text { As competências apresentam } \\
\text { potencial para orientar a gestão } \\
\text { da sustentabilidade, mas, } \\
\text { se estiverem desarticuladas } \\
\text { de suas premissas, gerarão } \\
\text { processos desintegrados, } \\
\text { que tendem a acarretar falta } \\
\text { de coesão estratégica. Essa } \\
\text { situação confluiria para prejuízos } \\
\text { econômicos, sociais e ambientais } \\
\text { ainda maiores que os já existentes }\end{array}$ \\
\hline $\begin{array}{l}\text { MUNCK, } \\
\text { SOUZA e } \\
\text { SAGUI (2011) }\end{array}$ & $\begin{array}{l}\text { A gestão por } \\
\text { competências } \\
\text { e sua relação } \\
\text { com ações de } \\
\text { sustentabilidade }\end{array}$ & $\begin{array}{l}\text { Explorar a relação } \\
\text { entre gestão por } \\
\text { competências } \\
\text { e ações de } \\
\text { sustentabilidade }\end{array}$ & $\begin{array}{l}\text { Qualitativa, } \\
\text { exploratória e } \\
\text { bibliográfica }\end{array}$ & $\begin{array}{l}\text { Montibeller (2007) } \\
\text { e Markus, Cooper- } \\
\text { Thomas e Allpress } \\
\text { (2005) }\end{array}$ & $\begin{array}{l}\text { Os gestores apontam que a } \\
\text { gestão por competências foi, } \\
\text { consensualmente, admitida } \\
\text { como fator de forte influência } \\
\text { nas ações de sustentabilidade. } \\
\text { O desenvolvimento de } \\
\text { competências potencializa } \\
\text { práticas de gestão de pessoas que } \\
\text { permitem tomadas de decisão } \\
\text { que poderão ser orientadas por } \\
\text { preceitos sustentáveis }\end{array}$ \\
\hline $\begin{array}{l}\text { SILVEIRA, } \\
\text { KIKUCHI e } \\
\text { POLICENO } \\
(2013)\end{array}$ & $\begin{array}{l}\text { Inovação e } \\
\text { aprendizagem } \\
\text { organizacional } \\
\text { para a } \\
\text { sustentabilidade: } \\
\text { desenvolvimento } \\
\text { de competências } \\
\text { na indústria de } \\
\text { equipamentos } \\
\text { eletromédicos }\end{array}$ & $\begin{array}{l}\text { Apresentar as } \\
\text { principais ações } \\
\text { relacionadas com } \\
\text { a geração de } \\
\text { competências de } \\
\text { um conjunto de } \\
\text { nove empresas, } \\
\text { visando a torná-las } \\
\text { aptas a implantar } \\
\text { as inovações } \\
\text { necessárias para } \\
\text { sua adequação a } \\
\text { requisitos ambientais } \\
\text { aplicáveis }\end{array}$ & $\begin{array}{l}\text { Qualitativa, } \\
\text { com } \\
\text { proposição de } \\
\text { um projeto- } \\
\text { piloto, } \\
\text { entrevistas } \\
\text { estruturadas e } \\
\text { questionários } \\
\text { auto } \\
\text { administrados. }\end{array}$ & $\begin{array}{l}\text { Pesquisa de } \\
\text { levantamento: } \\
\text { Bryman (1995) }\end{array}$ & $\begin{array}{l}\text { São descritos os planos } \\
\text { e respectivos resultados } \\
\text { no desenvolvimento das } \\
\text { competências definidas como } \\
\text { necessárias, contemplando } \\
\text { aspectos psicossociais que } \\
\text { impactam o desempenho da } \\
\text { organização e que mobilizam as } \\
\text { inovações, visando à integração } \\
\text { dos múltiplos objetivos inerentes } \\
\text { de um projeto-piloto cujo objetivo } \\
\text { é apoiar o desenvolvimento } \\
\text { sustentável }\end{array}$ \\
\hline $\begin{array}{l}\text { STEFANO e } \\
\text { ALBERTON } \\
(2015)\end{array}$ & $\begin{array}{l}\text { Competências } \\
\text { para } \\
\text { sustentabilidade } \\
\text { e governança } \\
\text { nas cooperativas } \\
\text { agroindustriais: } \\
\text { uma proposta de } \\
\text { análise }\end{array}$ & $\begin{array}{l}\text { Analisar a relação } \\
\text { de competências } \\
\text { voltadas à } \\
\text { sustentabilidade de } \\
\text { quatro cooperativas } \\
\text { agroindustriais } \\
\text { envolvidas com a } \\
\text { sustentabilidade }\end{array}$ & $\begin{array}{l}\text { Alfa de } \\
\text { Cronbach, } \\
\text { ANOVA, Test } \\
\text { T, Análises } \\
\text { Fatoriais e } \\
\text { Análises de } \\
\text { Cluster }\end{array}$ & $\begin{array}{l}\text { Wiek, Withycombe } \\
\text { e Redman (2011) } \\
\text { e Fleury e Fleury } \\
\text { (2004; 2005) }\end{array}$ & $\begin{array}{l}\text { As competências para a } \\
\text { sustentabilidade ainda não } \\
\text { estão totalmente internalizadas } \\
\text { nos aspectos estratégicos } \\
\text { (missão, visão e valores, bem } \\
\text { como competências distintivas, } \\
\text { individuais) nas cooperativas } \\
\text { investigadas, bem como nas } \\
\text { ações operacionais e em suas } \\
\text { estratégias organizacionais }\end{array}$ \\
\hline
\end{tabular}

Fonte: Elaborado pelos autores (2016). 
Conforme os estudos identificados na revisão sistêmica da literatura e os dados apresentados nos artigos voltados à mensuração e à abordagem das competências organizacionais de gerentes e colaboradores com foco na sustentabilidade organizacional, foram identificadas oito pesquisas relevantes e enquadradas nos critérios de seleção apontados.

O estudo proposto por Brunstein, Scartezini e Rodrigues (2010) trata de uma experiência de desenvolvimento de gestores em uma instituição financeira que se tornou destaque na mídia e passou a ser reconhecida como ator social destacado em seu campo organizacional por levar à frente a ideia de inserir a sustentabilidade na prática dos negócios. A referida organização criou um modelo educativo que fomentou, entre outras iniciativas, a instituição do Programa de Desenvolvimento de Líderes para a Sustentabilidade (PDLS). O resultados revelam um programa robusto, crítico e ambicioso em seu propósito, com uma proposta fundamentada em princípios construtivistas e na pedagogia da ação. O projeto é uma tentativa eficaz na busca de instrumentos, processos, projetos e ações que têm por intenção a utilização das competências individuais na busca da sustentabilidade no contexto empresarial. O discurso dos gestores se tornou competente, mas a ação nem sempre chega ao mesmo patamar de excelência. Os colaboradores e gestores adquiriram conhecimento e visão crítica, mas ainda enfrentam dificuldades para alinhar os objetivos do negócio com os princípios da sustentabilidade, considerando as competências. Ainda que a iniciativa gere competências societais, os paradoxos da ação permanecem.

Na investigação de Brunstein e Rodrigues (2011), buscou-se compreender como os gestores traduzem, em suas ações cotidianas, as diretrizes de sustentabilidade propostas pela empresa cuja visão estratégica é tornar-se referência em soluções ambientais. Assim, a concepção adotada de competência societal, considerando sua correlação com a sustentabilidade organizacional, é tomada como a capacidade de lidar com os impactos sociais e ambientais da gestão das organizações em múltiplos grupos de interesse e estabelecer diálogos entre empresas e sociedade em direção à construção de uma forma diferenciada de produção e gerenciamento. Os resultados apontam que a sustentabilidade é abordada como abstrata e distante da realidade prática e que sua operacionalização é condicionada por paradoxos e dilemas contraditórios. O desenvolvimento de competências organizacionais por parte dos gestores é algo em andamento. A distinção da competência entre discurso e prática deve ser considerada como forma de mudança na ação e nas posturas. Portanto, as competências societais devem ser desenvolvidas por meio de metodologias que favoreçam diálogos reflexivos, levando gestores a se confrontarem com os paradoxos, incentivando-os a buscar alternativas e respostas às situações-problema que permeiam a sustentabilidade.

No estudo de Demajorovic e Martão (2014), avaliou-se como práticas interdisciplinares em cursos de administração contribuem para o desenvolvimento de competências para a sustentabilidade, assim como os desafios e as perspectivas da inserção desses profissionais na administração da sustentabilidade nas organizações. Os resultados levantados pelos pesquisadores apontam que as práticas interdisciplinares contribuem para o desenvolvimento de competências para a sustentabilidade com visão sistêmica, pensamento crítico, diálogo com os diferentes atores envolvidos no processo e comprometimento pessoal de colaboradores e gestores. Essas mesmas competências foram identificadas pelos gestores de mercado quando considerada sua inserção no exercício profissional na área de gestão da sustentabilidade. Contraditoriamente, conforme a pesquisa revela, há falta de entendimento por parte dos gestores de mercado de como inserir profissionais na gestão sustentável das organizações, dificultando sua instrumentalização na prática.

A pesquisa realizada por Munck, Galleli e Souza (2013) propôs um framework representativo do acontecimento da ecoeficiência organizacional pela via da competência. Esse modelo se empenha em verificar o nível das competências que dão suporte à ecoeficiência com o intuito de indicar o potencial que a organização tem de ser ecoeficiente. A gestão por competências é uma alternativa concreta para compreender e integrar os setores da organização que permitirá formular respostas aos anseios sociais por ações organizacionais voltadas para a sustentabilidade. As competências que convergem para a operacionalização do Triple Bottom Line, de acordo com os autores, passa pelos seguintes aspectos: a inserção social, atingida por meio da junção das sustentabilidades econômica e social; a justiça socioambiental, obtida a partir da união das sustentabilidades social e ambiental; e a ecoeficiência, que se configura a partir da junção entre as sustentabilidades econômica e ambiental. Como base da construção do pensamento, as três competências-foco exploradas são primordiais para o alcance do desenvolvimento sustentável, que é considerado uma metacompetência.

A exemplo do estudo anterior, Munck, Munck e Souza (2011) propõem um novo framework, representando os processos necessários ao acontecimento da sustentabilidade organizacional. Toma-se como base epistemológica a Teoria do Agir Organizacional, de Maggi (2003), que concebe a organização como um processo de ações e decisões, em constante evolução e transformação, que se dissemina em todos os níveis. Assim, o sujeito produz a organização e é produzido por ela, por 
suas decisões. Nessa relação, a sustentabilidade é levada para o ambiente organizacional pelos indivíduos, ao adotarem posturas diferenciadas. Os autores defendem que a sustentabilidade organizacional não se dá por meio de ações isoladas, mas por meio de agires organizacionais integrados que orientam a criação de regras e o alinhamento e a coordenação de ações. Concluiu-se que as competências apresentam potencial para orientar a gestão da sustentabilidade, mas, se estiverem desarticuladas de suas premissas, gerarão processos desintegrados que tendem a acarretar falta de coesão estratégica.

Na pesquisa de Munk, Souza e Zagui (2011), explorou-se a relação da gestão por competências e ações de sustentabilidade em três grandes empresas, abordando especificamente gestores do departamento de recursos humanos. Nas empresas pesquisadas, a relação analisada foi considerada importante e existente. Entretanto, em duas delas notou-se uma baixa interligação de contribuições entre a gestão de competências e suas ações de sustentabilidade. Já em uma das empresas a relação entre sustentabilidade e competências societais foi identificada em quase todas as categorias analisadas. Nessa organização, foi possível perceber uma complementaridade entre a gestão de competências e o desenvolvimento de ações sustentáveis. Contudo, em todas ficou evidente que o tema sustentabilidade não é tratado diretamente pela área de recursos humanos, mas pela alta administração, refletindo em tomada de decisões distanciadas da esfera tática e operacional.

A pesquisa de Silveira, Kikuchi e Policeno (2013) objetivou apresentar as principais ações relacionadas com a capacitação de um conjunto de nove empresas, visando a torná-las aptas a implantar as inovações necessárias para sua adequação a requisitos ambientais aplicáveis, mantendo seu desempenho competitivo. Essas empresas fazem parte de um projeto-piloto cujo propósito é apoiar a sustentabilidade da indústria brasileira de equipamentos eletromédicos. A pesquisa descreve o planejamento e respectivos resultados no desenvolvimento das competências organizacionais definidas como necessárias, sobretudo aquelas relacionadas com o desempenho empresarial e sua adequação a padrões ambientalmente aceitáveis. O projeto analisado prevê a dinamização da aprendizagem nas empresas como caminho e alternativa para alcançar a sustentabilidade organizacional, superando os desafios do mercado e atendendo às demandas dos stakeholders. As estratégias empreendidas compreendem a priorização da valorização do capital intelectual para geração de vantagens competitivas sustentáveis, ao mesmo tempo que facilitam as ecoinovações e contribuem para o reconhecimento das habilidades do colaborador.

Por fim, o estudo de Stefano e Alberton (2015) aborda a relação de competências voltadas à sustentabilidade organizacional de quatro cooperativas agroindustriais envolvidas com ações voltadas para a sustentabilidade. Os resultados apontam que as competências para a sustentabilidade ainda não estão totalmente internalizadas nos aspectos estratégicos (missão, visão e valores, bem como competências distintivas, individuais) nas cooperativas investigadas, bem como nas ações operacionais e em suas estratégias organizacionais. A integração das áreas de interesse deve passar pela identificação e gestão de novas competências, ao mesmo tempo que estas devem estar vinculadas à estratégia organizacional. Os colaboradores que tenham seus respectivos comportamentos avaliados e valorizados por processos transparentes inseridos e disseminados pela aplicabilidade de um modelo de gestão de competências, quando solicitados a participar de realidades amparadas por premissas sustentáveis, estarão conscientes e mais bem preparados para exercer seu papel e contribuir, dessa forma, para a realização dos objetivos estratégicos da empresa.

\section{CONSIDERAÇÕES FINAIS}

Ao longo da presente pesquisa, buscou-se conhecer a relação estabelecida entre as competências societais e sustentabilidade organizacional, explorando estudos relevantes que versam sobre o tema, abordando as competências tanto de gestores quanto de colaboradores de empresas de variados ramos. Selecionaram-se estudos desenvolvidos entre os anos 2010 e 2015. Foram levantadas as principais contribuições sobre a temática central a partir da revisão sistemática, sendo os artigos selecionados compostos por empresas ligadas à temática da sustentabilidade.

Em geral, as pesquisas abordam a temática das competências organizacionais desenvolvidas em empresas de variados ramos e portes que empreendem ações com foco na articulação dos aspectos econômico, social e ambiental. As pesquisas, embasadas tanto em teorias que focam as competências quanto naquelas que tratam da sustentabilidade, compreendem ainda metodologias de pesquisa diferenciadas, baseadas em métodos mais específicos (MAGGI, 2003; BRYMAN, 1995).

Conforme observado, os estudos tratam de áreas distintas e com objetivos diferentes, mas reúnem discussões complementares e que agregam conhecimento às pesquisas referentes à temática. Por meio da revisão sistêmica, identificou-se que os 
estudos selecionados estabelecem uma ordem que auxilia em sua compreensão. Há estudos que abordam o distanciamento do discurso em relação à prática da sustentabilidade pela via das competências organizacionais, assim como os dilemas existentes entre as propostas dos gestores e sua operacionalização pelos colaboradores (BRUNSTEIN, SCARTEZINI e RODRIGUES, 2010; BRUNSTEIN e RODRIGUES, 2011). Outros estudos abordam, ainda, a formação de competências societais por meio de formação de novos profissionais (DEMAJOROVIC e MARTÃO, 2014), a proposição de frameworks representando os processos que levam à internalização da sustentabilidade e da ecoeficiência (MUNCK, GALLELI e SOUZA, 2013; MUNCK, MUNCK e SOUZA, 2011), assim como pesquisas que versam sobre a capacitação de pessoas com foco em sustentabilidade e gestão por competências, valorização de capital intelectual e estabelecimento de estratégias competitivas (MUNCK, SOUZA e SAGUI, 2011; SILVEIRA, KIKUCHI e POLICENO, 2013; STEFANO e ALBERTON, 2015).

Os resultados encontrados revelam, conforme estudos de Brunstein, Scartezini e Rodrigues (2010) e Brunstein e Rodrigues (2011), que o discurso que envolve a geração de competências organizacionais focadas em ações de sustentabilidade é distante da realidade prática e nem sempre produz efeitos que impactam a dimensão operacional das organizações. A iniciativa dos gestores nem sempre atinge o patamar de excelência a ponto de distanciar os paradoxos e os dilemas contraditórios que envolvem a temática, sendo considerada em construção. Os colaboradores, ainda que adquiram conhecimento e capacitação, enfrentam desafios, sobretudo em relação à realização da confluência dos objetivos organizacionais e dos princípios da sustentabilidade.

Em um estudo isolado, Demajorovic e Martão (2014) identificaram que práticas interdisciplinares contribuem para o desenvolvimento de competências voltadas à sustentabilidade com o auxílio do comprometimento de colaboradores e gestores, muito embora exista falta de entendimento por parte dos gestores de como profissionais com formação específica nessa área possam ser inseridos no mercado e nas organizações.

Ao buscar propor um modelo de representação que descreva os processos necessários ao acontecimento da sustentabilidade organizacional por meio das competências desenvolvidas tanto por colaboradores quanto por gestores, Munck, Munck e Souza (2011) elaboram um framework baseado na Teoria do Agir Organizacional, de Maggi (2003). Segundo essa teoria, a organização é resultado de um processo contínuo de ações e decisões tomadas por indivíduos, incluindo aquelas voltadas para a adoção de atitudes centradas na sustentabilidade. Tomando como base o mesmo modelo de representação, Munck, Galleli e Souza (2013) elaboram um framework representativo do acontecimento da ecoeficiência organizacional pela via da competência. De acordo com os autores, as competências societais contribuem para a operacionalização do conceito do tripé da sustentabilidade, contemplando tanto aspectos econômicos quanto sociais e ambientais. Exploram-se as competências que dão suporte ao acontecimento da ecoeficiência com o intuito de verificar o potencial da empresa em adotar ações e direcionamento pautado pela ecoeficiência.

E, por fim, as demais pesquisas exploraram as estratégias competitivas e suas relações com a geração de competências societais e sustentabilidade. A pesquisa de Munck, Souza e Zagui (2011) abordou com mais profundidade a gestão por competências e as ações de sustentabilidade, identificando se nas empresas estudadas a relação estabelecida era significativamente importante e existente. O segundo estudo, de Silveira, Kikuchi e Policeno (2013), tratou de apresentar as principais ações desenvolvidas por empresas com foco em capacitação, visando a torná-las aptas a implantar as inovações necessárias para sua adequação a requisitos ambientais aplicáveis, mantendo seu desempenho competitivo. Segundo o estudo, a aprendizagem e a capacitação, com consequente geração de competências aos colaboradores, são vistas como alternativa para que se alcance a sustentabilidade organizacional. E a pesquisa de Stefano e Alberton (2015) visa a compreender as competências focadas em sustentabilidade e sua correlação e impacto nos aspectos estratégicos das empresas objeto de estudo, abordando a internalização e a operacionalização destes nas estratégias organizacionais. Os autores apontam que a integração da gestão de novas competências deve estar vinculada às estratégias organizacionais.

Assim, considerando as pesquisas selecionadas de acordo com os critérios de inclusão e exclusão, aponta-se que os estudos exploram diferentes segmentos e áreas de conhecimento, compreendidos em um contexto maior, que trata da geração de competências societais para a sustentabilidade organizacional. Destaca-se que, embora se reconheça a relevância da formação de competências focadas em sustentabilidade, o discurso e a realidade prática ainda caminham em sentidos contrários, e nem sempre há conformidade entre o que se pretende realizar e o que é efetivamente instrumentalizado. A gestão das competências, necessárias para o alinhamento da organização às premissas da sustentabilidade, ainda necessita de desenvolvimento e aprimoramento, buscando convergir as aspirações dos indivíduos com as metas e objetivos empresariais, rumo à sustentabilidade organizacional. 


\section{REFERÊNCIAS}

ALMEIDA, F. Os desafios da sustentabilidade: uma ruptura urgente. Rio de Janeiro: Elsevier, 2007.

AUTIO, E. et al. Entrepreneurial innovation: the importance of context. Research Policy, v. 43, p. 1097-1108, 2014.

BRUNSTEIN, J; BOULOS, S. A dimensão política da competência dos executivos em sua relação com stakeholders. In: XXXIII ENCONTRO NACIONAL DA ANPAD. Anais..., São Paulo, 2009.

BRUNSTEIN, J.; RODRIGUES, A. L. Sustentabilidade, sentido e ação: contribuições para o desenvolvimento da competência societal. In: III ENCONTRO DE GESTÃO DE PESSOAS E RELAÇÕES DE TRABALHO. Anais..., João Pessoa, 2011.

BRUNSTEIN, J.; SCARTEZINI, V. N.; RODRIGUES, A. L. Competência societal: uma experiência corporativa de ação educativa voltada ao desenvolvimento de gestores para sustentabilidade. In: XXXIV ENCONTRO DA ANPAD. Anais..., Rio de Janeiro, 2010.

BRUNSTEIN, J.; SCARTEZINI, V. N.; RODRIGUES, A. L. Sustentabilidade na educação corporativa e o desenvolvimento de competências societais. Revista O\&S, v. 19, n. 63, p. 583-598, 2012.

BRYMAN, A. Research methods and organization studies. Londres: Routledge, 1995.

CALLADO, A. L. C. Modelo de mensuração de sustentabilidade empresarial: uma aplicação em vinícolas localizadas na Serra Gaúcha. Tese (Doutorado em Agronegócios), Universidade Federal do Rio Grande do Sul, Porto Alegre, 2010.

CARVALHO, A. C. V.; STEFANO, S. R.; MUNCK, L. Competências voltadas à sustentabilidade organizacional: um estudo de caso em uma indústria exportadora. Gestão \& Regionalidade, v. 3, n. 1, p. 33-48, 2015.

CARVALHO, A. P.; BARBIERI, J. C. Innovation for sustainability: overcoming the productivity of the sugar-and-ethanol industry's conventional system. Journal of Technology Management \& Innovation, v. 5, n. 4, p. 83-94, 2010.

CASTRO, A. A. Revisão sistemática e meta-análise, 2001. Disponível em: <http://metodologia.org/wp-content/uploads/2010/08/meta1. PDF>. Acesso em: 10 set. 2015.

DEMAJOROVIC, J.; MARTÃO, S. D. Competências e inserção profissional de administradores em sustentabilidade. Pretexto, Belo Horizonte, v. 15 , p. $48-66,2014$

DUBOIS, D. D.; ROTHWELL, W. J. An overview of competencybased management practices: competency-based human resource management. Davies-Black Publishing, Mountain View, Califórnia, 2004. p. $15-40$.

DUTRA, J. S. Competências: conceitos e instrumentos para a gestão de pessoas na empresa moderna. São Paulo: Atlas, 2012.

ELKINGTON, J. Cannibals with forks: the triple bottom line of 21 st century business. Oxford: Capstone Publishing Limited, 1999.

FLEURY, A. C. C.; FLEURY, M. T. L. Estratégias empresariais e formação de competências: um quebra-cabeça caleidoscópico da indústria brasileira. São Paulo: Atlas, 2008.

FLEURY, M. T. L.; FLEURY, A. C. C. Alinhando estratégia e competências. Revista de Administração de Empresas, v. 44, n. 1, p. 44-57, jan./mar. 2004.
FLEURY, M. T. L.; FLEURY, A. C. C. In search of competence: aligning strategy and competences in the telecommunications industry. The International Journal of Human Resource Management, v. 16, n. 9, p. 1640-1655, 2005.

GREENWOOD, M. Stakeholder engagement: beyond the myth of corporate responsibility. Journal of Business Ethics, v. 74, p. 315-327, 2007.

HAAN, G. The BLK "21" programme in Germany: a "Gestaltungskompetenz" - based model for education for sustainable development. Environmental Education Reserch, Londres, v. 12, n. 1, p. 19-32, 2006. HANSEN, M. H.; PERRY, L. T.; REESE, C. S. A Bayesian operationalization of the resource-based view. Strategic Management Journal, Baffins Lane, v. 25, p. $1279-1295,2004$.

HOLLAND, T. P.; RITVO, R. A.; KOVNER, A. R. Improving board effectiveness. Chicago: American Hospital Publishing Inc., 1997.

HUNT, S. D.; MORGAN, R. M. The comparative advantage theory of competition. Journal of Marketing, Chicago, v. 59, n. 2, p. 1-15, 1995.

JAMALI, D. Insights into the triple bottom line integration from a learning organization perspective. Business Process Management Journal, v. 12, n. 6 , p. $809-821,2006$

KLEEF, J. A. G.; ROOME, N. J. Developing capabilities and competence for sustainable business management as innovation: a research agenda. Journal of Cleaner Production, v. 15, n. 1, p. 38-51, 2007.

KRAJNC, D.; GLAVIC, P. A model for integrated assessment of sustainable development. Resources, Conservation and Recycling, v. 43, n. 2, p. 189-208, 2005.

LÉON-SORIANO, R.; MUNÕZ-TORRES, M. J.; CHALMETA-ROSALEN, R. Methodology for sustainability strategic planning and management. Industrial Management \& Data Systems, v. 110, n. 2, p. 249-268, 2010.

LORENZETTI, D. H.; CRUZ, R. M.; RICIOLI, S. Estratégia empresarial e sustentabilidade: um modelo integrador. Revista da Pós-graduação: Administração, v. 2, n. 3, p. 33-57, 2008.

MAGGI, B. De l'agir organisationnel: un point de vue sur le travail, le bien-être, l'apprentissage. Toulouse: Octarès Editions, 2003.

MARKUS, L. H.; COOPER-THOMAS, H. D.; ALLPRESS, K. N. Confunded by competencies? An evaluation of the evolution and use of competency models. New Zealand Journal of Psychology, v. 34, n. 2, p. 117-126, 2005.

MONTIBELLER F., G. Empresas, desenvolvimento e ambiente: diagnóstico e diretrizes de sustentabilidade. Barueri: Manole, 2007.

MUNCK, L.; GALLELI, B.; SOUZA, R. B. Competências para a sustentabilidade organizacional: a proposição de um framework representativo do acontecimento da ecoeficiência. Produção, v. 23, n. 3, p. 652-669, jul./set. 2013.

MUNCK, L.; MUNCK, M. M.; SOUZA, R. B. Sustentabilidade organizacional: a proposição de uma framework representativa do agir competente para seu acontecimento. In: XXXV ENCONTRO DA ANPAD. Anais..., Rio de Janeiro, 2011.

MUNCK, L.; SOUZA, R. B. Gestão por competências e sustentabilidade empresarial: em busca de um quadro de análise. Gestão e Sociedade, v. 3, n. 6 , p. 254-287, 2009. 
MUNCK, L.;SOUZA, R. B.;SAGUI, C. Agestão por competências esua relação com ações de sustentabilidade. Pretexto, Belo Horizonte, v. 12, n. 4, p. 55-79, 2011.

PETRINI, M.; POZZEBON, M. Integrating sustainability into business practices: learning from Brazilian firms. Brasilian Administration Review, Curitiba, v. 7, n. 4, p. 362-378, 2010.

RUTH, D. Frameworks of managerial competence: limits, problems and suggestions. Journal of European Industrial, v. 30, n. 3, p. 206-226, 2006.

SANDBERG, J. Understanding human competence at work: an interpretative approach. Academy of Management Journal, v. 43, n. 1, p. 9-25, 2000.

SANDBERG, J.; DALL'ALBA, G. Re-framing competence development at work. In: CASTLETON, G.; GERBER, R.; PILLAY, H. Improving workplace learning: emerging international perspectives. Nova York: Nova Science Publisher, 2006.

SAVITZ, A. W.; WEBER, K. A empresa sustentável: o verdadeiro sucesso é lucro com responsabilidade social e ambiental. Rio de Janeiro: Elsevier, 2007.

SCHALTEGGER, S., HANSEN, E. G., LUDEKE-FREUND, F. L. Business models for sustainability: origins, present research, and future avenues. Organizations and Environment, v. 29, n. 1, p. 3-10, 2016.

SHRIVASTANA, P. Pedagogy of passion for sustainability. Academy of Management Learning and Education, v. 9, n. 3, p. 443-455, set. 2010.
SILVEIRA, M. A.; KIKUCHI, L. S.; POLICENO, C. A. Inovação e aprendizagem organizacional para a sustentabilidade: desenvolvimento de competências na indústria de equipamentos eletromédicos. Management and Connections Journal, Vitória, v. 2, n. 1, p. 76-93, 2013.

SPRINGETT, D. Education for sustainability in the business studies curriculum: a call for a critical agenda. Business Strategy and the Environment, v. 14, p. 146-159, 2005.

STEFANO, S. R.; ALBERTON, A. Competências para sustentabilidade e governança nas cooperativas agroindustriais: uma proposta de análise. In: XXXIV ENCONTRO DA ANPAD. Anais..., Belo Horizonte, set. 2015.

WIEK, A.; WITHYCOMBE, L.; REDMAN, C. L. Key competencies in sustainability: a reference framework for academic program development. Sustainability Science, v. 6, p. 203-218, 2011.

WILSON, A.; LENSSEN, G.; HIND, P. Leadership qualities and management competencies for corporate responsibility: a research report for the European business in society. EABIS, UK, jul. 2006.

WORLD BUSINESS COUNCIL FOR SUSTAINABLE DEVELOPMENT (WBCSD). A eco-eficiência: criar mais valor com menos impacto. Lisboa, 2000.

WORLD BUSINESS COUNCIL FOR SUSTAINABLE DEVELOPMENT (WBCSD). 2008. Disponível em: <http://www.wbcsd.org>. Acesso em: 12 dez. 2015.

Edson Luis Kuzma

Mestre Interdisciplinar em Desenvolvimento Comunitário pela Universidade Estadual do Centro Oeste (UNICENTRO), Irati, PR, Brasil.

E-mail: edson.kuzma@gmail.com

Sergio Luis Dias Doliveira

Doutor em Administração pela Universidade Federal do Paraná (UFPR).Professor Titular na UNICENTRO, Irati, PR, Brasil. E-mail: sldd@uol.com.br

Adriana Queiroz Silva

Doutoranda em Administração pela Universidade Positivo (UP).Professora Titular na UNICENTRO, Irati, PR, Brasil. E-mail: aqueirozsilva@uol.com.br 